American Journal of Applied Sciences 7 (2): 221-226, 2010

ISSN 1546-9239

(C) 2010 Science Publications

\title{
Modeling of an Industrial Riser in the Fluid Catalytic Cracking Unit
}

\author{
Mehran Heydari, Habib Ale Ebrahim and Bahram Dabir \\ Department of Chemical Engineering, Amir Kabir University of Technology, \\ P.O. Box 15875-4413, 424, Hafez Ave, Tehran, Iran
}

\begin{abstract}
Problem statement: The aim of this study is to obtain a model that can simulate the performance of an industrial fluid catalytic cracking unit in steady state. Approach: The reactions in the riser occur in a transported bed with the fluid and the solids in ideal plug flow. One of the main advantages of the model is that it does not include any partial differential equations. This facilitates the solution of the equations and makes the model particularly suitable for control studies. Results: To simulate the FCC riser, the four-lump model involved gas oil, gasoline, light gas and coke (to predict the Gas oil conversion and the product distribution) has been developed. Conclusion: Simulation studies are performed to investigate the effect of changing various process variables, such as temperature, catalyst circulation rate and gasoil feed rate. The calculated data of the product distribution were agreed well with the experimental results.
\end{abstract}

Key words: FCC, riser reactor, riser simulation, four-lump kinetic model, catalytic cracking

\section{INTRODUCTION}

The Fluid Catalytic Cracking (FCC) unit is one of the most important processes in the petroleum refining industry. Heavy petroleum fractions are catalytically cracked to lower molecular weight products. In the FCC riser, lift steam pushes the dense catalyst bed upward from the riser base to the feed injection point. The feed enters as liquid droplets along with atomizing steam, contact the hot catalyst and rapidly evaporates. As the suspension of catalyst powder in reactant gases rises upward, the gas is cracked to lighter hydrocarbons (gasoline and light gases) and coke. The coke is deposited on the catalyst, which is transported out of the riser and into the regenerator, where the coke is burned off the catalyst in a combustion environment. The hot regenerated catalyst is then reinjected into the base of the riser (Berry et al., 2004). In this way similar components are grouped into a few "cuts" or "lumps. The number of lumps of the proposed models for catalytic cracking reactions has been consecutively increasing to obtain a more detailed prediction of product distribution (Bollas et al., 2007). In the first kinetic model (3-lump), proposed by Weekman (1968), reactants and products were lumped into three major groups: Gas oil, gasoline and light gas plus coke. Lee et al. (1989b) and Lee et al. (1989a) took one step forward by dividing the light gas plus coke lump into two different lumps $\mathrm{C}_{1}-\mathrm{C}_{4}$ gas and coke, developing the first 4-lump models for fluid catalytic cracking. Advancing the lumping methodology, Corella and Frances (1991) developed a 5-lump models, in which the gas-oil lump was divided into its heavy and light fractions. Dupain et al. (2006) simplified the 5lump model of Corella and Frances (1991) for the specific case of the catalytic cracking of aromatic gas oil, by reducing the reactions involved in the lumping scheme. Another 5-lump model was developed by Kraemer et al. (1991) in which the 3-lump model of Weekman (1968) was modified by splitting the gas oil lump into aromatic, paraffinic and naphthtenic lumps. Ancheyta-Juarez et al. (1999) followed a different approach in their 5-lump models development, in which they considered the gas oil as one lump, but divided the gas lump into two lumps (liquefied product gas and dry gas). Hagelberg et al. (2002) expanded the 5-lump model of Ancheyta-Juarez et al. (1999) to an 8-lump model by dividing the gasoline fraction into paraffins, olefins, naphthenes and aromatics. With presence of the high efficiency feed injection system in modern FCC units cause all cracking in the riser occur during the short time (about $1-5 \mathrm{sec})$. Therefore based on this fact, it is explainable that many of the models found in the literature (Arandes and de Lasa, 1992; Arbel et al., 1995; Han and Chung, 2001; Ali and Rohani, 1997; Bollas et al., 2007), describe the riser reactor, with one-dimensional mass, energy and chemical species balances, so in the

Corresponding Author: Mehran Heydari, Department of Chemical Engineering, Amir Kabir University of Technology, P.O. Box 15875-4413, 424, Hafez Ave, Tehran, Iran Tel:+989121752593 
present research, a one-dimensional, adiabatic model for the FCC unit riser has been developed that combines predicative riser hydrodynamic model with a four-lump kinetic model.

\section{MATERIALS AND METHODS}

The model is based on the schematic flow diagram presented in Fig. 1. It is assumed that gas oil is converted to gasoline range hydrocarbons, light gases and coke in the riser reactor, which is considered to be a transported bed. The upper fluidized bed immediately above the riser acts as a disengaging chamber where vapor products and heavy components are separated from the catalyst using stripping steam. The only effect of the stripping process is to remove hydrocarbon gases adsorbed inside the pellets before the spent catalyst is sent to the regenerator. Fresh gas oil is brought into contact with the hot regenerated catalyst at the entrance of the riser which leads to the vaporization of gas oil. The inlet zone is considered to be the most complex part of the riser.

This is attributed to the presence of high turbulence, high temperature and concentration gradients and flow inhomogeneity. Vaporization of the feed, according to plant data (Ali and Rohani, 1997) it takes about $0.1 \mathrm{sec}$ to fully vaporize the feed. Therefore, it is justifiable to assume instantaneous vaporization of the feed. In this study, all the cracking reactions are considered to take place in the riser. This assumption is reasonable since the zeolite catalysts, the reaction promoters and the multifunction catalyst additives, highly accelerate the cracking reactions rates. Furthermore, the coke formation will sharply decrease the catalyst activity towards the exit of the riser.

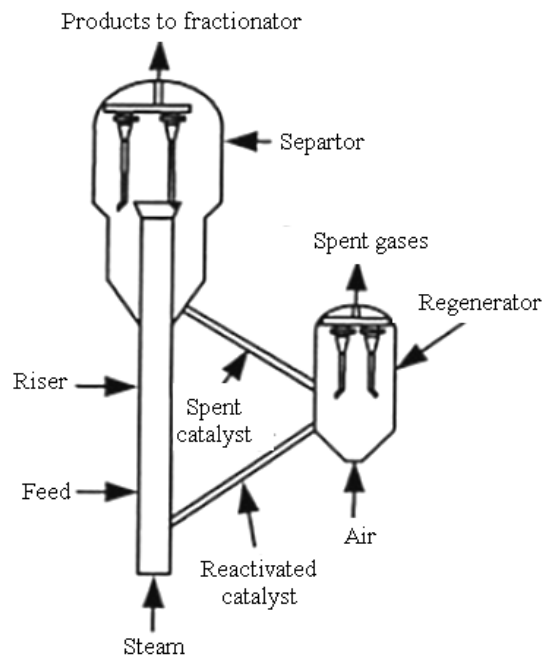

Fig. 1: Schematic diagram of catalytic cracking unit
The four-lump model involved gas oil, gasoline, light gas and coke has been shown in Fig. 2. The advantage of this scheme is that the coke and light gases are represented by two separated lumps. Where A, B, C and D represent gasoil, gasoline, coke and light hydrocarbon gases, respectively. According of this scheme, a part of gasoline is also converted to light gases and coke. It is assumed that the cracking of gas oil is a second-order reaction but the cracking of gasoline is a first-order reaction and the reactions take place only in the gas phase. The deactivation of catalyst due to coke deposition has been the subject of many research work. In this study, the deactivation kinetic model due to Weekman (1968) is chosen because of its implicity, popularity in FCC modeling and abundance of data available in the literature. In this scheme, the decay of the catalyst activity due to coke deposition is represented by a function, $\phi_{\mathrm{R}}$, which depends on the temperature and catalyst residence time, $\mathrm{t}_{\mathrm{c}}$ :

$\phi_{\mathrm{R}}=\exp \left(-\alpha . \mathrm{t}_{\mathrm{c}}\right)$

where, $\alpha$ is the catalyst decay coefficient related to the riser temperature by an Arrhenius equation:

$\alpha=\alpha_{\circ} \exp \left(-\frac{E}{\mathrm{RT}}\right)$

In order to develop a mathematical model for this system the following assumptions are introduced:

- One-dimensional transported plug flow reactor prevails in the riser without radial and axial dispersion and the riser wall is adiabatic

- Feed viscosity and heat capacities of all components are constant

- In each section of riser, the catalyst and gas have a same temperature

- Instantaneous vaporization occurred in entrance of riser

- All cracking reactions are considered to take place in the riser

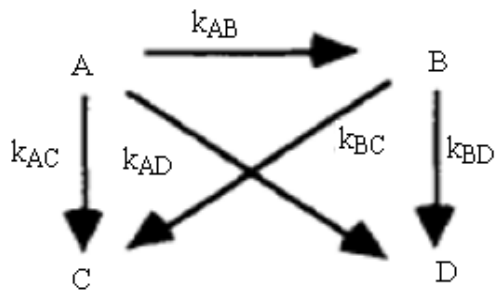

Fig. 2: Four-lumped model 
Steady state mass and energy balance: Applying the conservation principles and assuming plug flow in the riser, the mass and heat balances in dimensionless form are:

Gas oil:

$$
\frac{\mathrm{dy}_{\mathrm{A}}}{\mathrm{dz}}+\frac{\phi_{\mathrm{R}} \mathrm{A}_{\mathrm{R}}(1-\varepsilon) \rho_{\mathrm{S}} \mathrm{L}_{\mathrm{R}}}{\mathrm{F}_{\mathrm{gR}}}\left[\mathrm{K}_{\mathrm{AB}}+\mathrm{K}_{\mathrm{AC}}+\mathrm{K}_{\mathrm{AD}}\right] \mathrm{y}_{\mathrm{A}}^{2}=0
$$

Gasoline:

$$
\frac{d y_{B}}{d z}+\frac{\phi_{R} A_{R}(1-\varepsilon) L_{R} \rho_{S}}{F_{g R}}\left[\left(K_{B C}+K_{B D}\right) y_{B}-K_{A B} y_{A}^{2}\right]=0
$$

Light hydrocarbon gases:

$$
\frac{d y_{D}}{d z}-\frac{\varphi_{R} A_{R}(1-\varepsilon) L_{R} \rho_{S}}{F_{g R}}\left[K_{B D} y_{B}+K_{A D} y_{A}^{2}\right]=0
$$

Coke:

$$
\frac{d y_{C}}{d z}-\frac{\varphi_{R} A_{R}(1-\varepsilon) L_{R} \rho_{S}}{F_{g R}}\left[K_{B C} y_{B}+K_{A C} y_{A}^{2}\right]=0
$$

The entrance Temperature $\left(T_{R}\right)$ is obtained by solving Eq. 14:

At $\mathrm{Z}=0$ :

$$
\begin{aligned}
& \mathrm{F}_{\mathrm{S}} \mathrm{CP}_{\mathrm{S}}\left(\mathrm{T}_{\mathrm{R}}-\mathrm{T}_{\mathrm{S}}\right)+\mathrm{F}_{\mathrm{gL}} \mathrm{CP}_{\mathrm{gL}}^{\mathrm{L}}\left(\mathrm{T}_{\text {vap }}-\mathrm{T}_{\mathrm{f}}\right)+ \\
& \mathrm{F}_{\mathrm{gL}} \mathrm{CP}_{\mathrm{gL}}^{\mathrm{V}}\left(\mathrm{T}_{\mathrm{R}}-\mathrm{T}_{\text {vap }}\right)+\mathrm{F}_{\mathrm{gL}} \Delta \mathrm{H}_{\text {vap }}+\mathrm{F}_{\mathrm{ds}} C \mathrm{p}_{\mathrm{ds}}\left(\mathrm{T}-\mathrm{T}_{\mathrm{ds}}\right)=0
\end{aligned}
$$

At $\mathrm{Z}=\mathrm{L}$ :

$$
\begin{aligned}
& \frac{\mathrm{d} T}{\mathrm{dZ}}+\frac{\varphi_{\mathrm{R}}(1-\varepsilon) \rho_{\mathrm{S}} \mathrm{L}_{\mathrm{R}} \mathrm{A}_{\mathrm{R}}}{\left(\mathrm{F}_{\mathrm{S}} \mathrm{CP}_{\mathrm{S}}+\mathrm{F}_{\mathrm{g}} \mathrm{CP}_{\mathrm{g}}\right) \cdot \mathrm{t}_{\mathrm{ref}}} . \\
& \left(\mathrm{y}_{\mathrm{A}}^{2}\left[\begin{array}{l}
\mathrm{K}_{\mathrm{AB}}\left(\Delta \mathrm{H}_{\mathrm{AB}}\right)+ \\
\mathrm{K}_{\mathrm{AC}}\left(\Delta \mathrm{H}_{\mathrm{AC}}\right)+\mathrm{K}_{\mathrm{AD}}\left(\Delta \mathrm{H}_{\mathrm{AD}}\right)
\end{array}\right]+\mathrm{y}_{\mathrm{B}}\left[\begin{array}{l}
\mathrm{K}_{\mathrm{BC}}\left(\Delta \mathrm{H}_{\mathrm{BC}}\right)+ \\
\mathrm{K}_{\mathrm{BD}}\left(\Delta \mathrm{H}_{\mathrm{BD}}\right)
\end{array}\right]\right)
\end{aligned}
$$

With the boundary conditions, at $\mathrm{Z}=0$ :

$$
\begin{aligned}
& \mathrm{y}_{\mathrm{A}}(0)=1 \\
& \mathrm{y}_{\mathrm{i}}(0)=0 \\
& \mathrm{~T}(0)=\mathrm{T}_{\mathrm{R}} \\
& \mathrm{i} \quad=\mathrm{B}, \mathrm{C} \text { and } \mathrm{D}
\end{aligned}
$$

\section{RESULTS}

In this study, the ordinary differential equations (Eq. 10-13 and 15) must be solved by Runge-Kutta order 4, because the equations are not too stiff, so it has been developed a Matlab code for this purpose. The kinetic parameters for cracking reactions and catalyst deactivation from the literature (Ahari et al., 2008) are given in Table 1 . The typical value of the hydrodynamic parameters used in this study can be found in Table 2 and 3, respectively (Ali and Rohani, 1997).

In this study the simulation results for the steady state are presented and discussed. The plant operating conditions data supplied by Ali and Rohani (1997), can be found in Table 4. Four case studies were designed to cover a broad range of operating conditions. The four case studies represent different feedstock conditions. Table 5 shows the predictions of model are compared with all of exist plant data, According to Table 5 a good agreement between the plant data and the model prediction is observed.

Table 1: Kinetic parameters

\begin{tabular}{lrlc}
\hline Reaction & \multicolumn{1}{c}{$\mathrm{K}_{0}$} & $\mathrm{E}\left(\mathrm{kJ} \mathrm{mol}^{-1}\right)$ & $\Delta \mathrm{H}\left(\mathrm{kJ} \mathrm{Kg}^{-1}\right)$ \\
\hline Gas oil to gasoline & 1150.00000 & 59.66 & 393 \\
Gas oil to light gases & 73.60000 & 47.82 & 795 \\
Gas oil to coke & 1.79000 & 30.95 & 1200 \\
Gasoline to light gases & 426.00000 & 68.83 & 1150 \\
Gasoline to coke & 0.00059 & 57.74 & 151 \\
Catalyst deactivation & 59100.00000 & 67.21 & - \\
\hline
\end{tabular}

Table 2: Molecular weight and heat capacities

\begin{tabular}{lll}
\hline Species & $\mathrm{MW}\left(\mathrm{kg} \mathrm{kmol}^{-1}\right)$ & $\mathrm{C}_{\mathrm{p}}\left(\mathrm{kJ} \mathrm{kg}^{-1} \cdot \mathrm{k}\right)$ \\
\hline Gas oil & 333.0 & 3.300 \\
Gasoline & 106.7 & 3.300 \\
Light gases & 40.0 & 3.300 \\
Coke & 14.4 & 1.087 \\
Steam & 18.0 & 1.900 \\
\hline
\end{tabular}

Table 3: Riser hydrodynamic parameters

\begin{tabular}{ll}
\hline Gas superficial velocity $\left(\mathrm{m} \mathrm{sec}^{-1}\right)$ & 6.1 \\
Gas oil vaporization temperature $(\mathrm{k})$ & 698 \\
Viscosity of gas $\left(\mathrm{N} . \mathrm{S} \mathrm{m}^{-2}\right)$ & $1.4 \times 10^{-5}$ \\
Gas oil enthalpy of vaporization $\left(\mathrm{kJ} \mathrm{kg}^{-1}\right)$ & 190 \\
Riser diameter (m) & 0.8 \\
Riser height (m) & 33 \\
\hline
\end{tabular}

Table 4: Industrial riser operating conditions

\begin{tabular}{lrrrr}
\hline & Case 1 & Case 2 & Case 3 & Case 4 \\
\hline Feed rate $\left(\mathrm{kg} \mathrm{sec}^{-1}\right)$ & 25.70 & 26.90 & 23.60 & 19.95 \\
Feed quality $(\mathrm{API})$ & 21.76 & 22.98 & 22.73 & 22.28 \\
COR $\left(\mathrm{kg} \mathrm{kg}^{-1}\right)$ & 6.33 & 5.43 & 6.07 & 7.20 \\
Inlet pressure $(\mathrm{kPa})$ & 180.00 & 180.00 & 180.00 & 180.00 \\
Feed temperature $(\mathrm{K})$ & 494.00 & 494.00 & 494.00 & 494.00 \\
Catalyst temperature $(\mathrm{K})$ & 1033.00 & 1004.00 & 1006.00 & 960.00 \\
Steam $\left(w w_{0}\right)$ & 5.50 & 5.00 & 5.75 & 7.00 \\
Steam temperature $(\mathrm{K})$ & 773.00 & 773.00 & 773.00 & 773.00 \\
\hline
\end{tabular}


Am. J. Applied Sci., 7 (2): 221-226, 2010

Table 5: Comparison of this work predicted results with industrial plant data

\begin{tabular}{|c|c|c|c|c|c|c|c|c|c|c|c|c|}
\hline & \multicolumn{3}{|l|}{ Case 1} & \multicolumn{3}{|l|}{ Case 2} & \multicolumn{3}{|l|}{ Case 3} & \multicolumn{3}{|l|}{ Case 4} \\
\hline & Plant & Calc. & dev. $(\%)$ & Plant & Calc. & dev. $(\%)$ & Plant & Calc. & dev. $(\%)$ & Plant & Calc. & dev. $(\%)$ \\
\hline Gasoline yield (wt\%) & 46.90 & 42.19 & -10.01 & 42.79 & 40.47 & -5.42 & 41.78 & 39.01 & -6.62 & 43.88 & 37.61 & -14.28 \\
\hline Coke yield (wt\%) & 5.34 & 5.31 & -0.56 & 5.43 & 5.71 & 5.15 & 5.69 & 5.95 & 4.50 & 5.83 & 6.55 & 12.30 \\
\hline Outlet temperature (k) & 808.00 & 807.50 & -0.05 & 805.00 & 760.00 & -5.60 & 806.00 & 774.00 & -3.97 & 795.00 & 764.00 & -3.90 \\
\hline
\end{tabular}

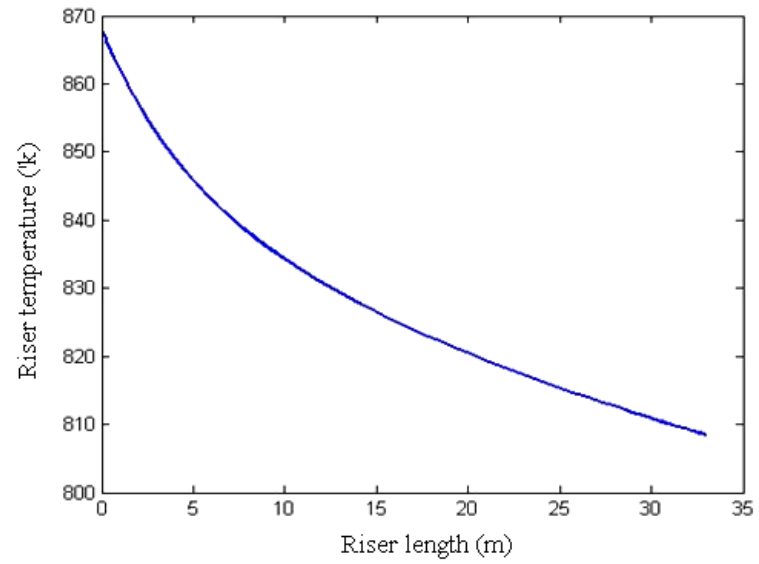

Fig. 3: Steady-state temperature profile in the riser

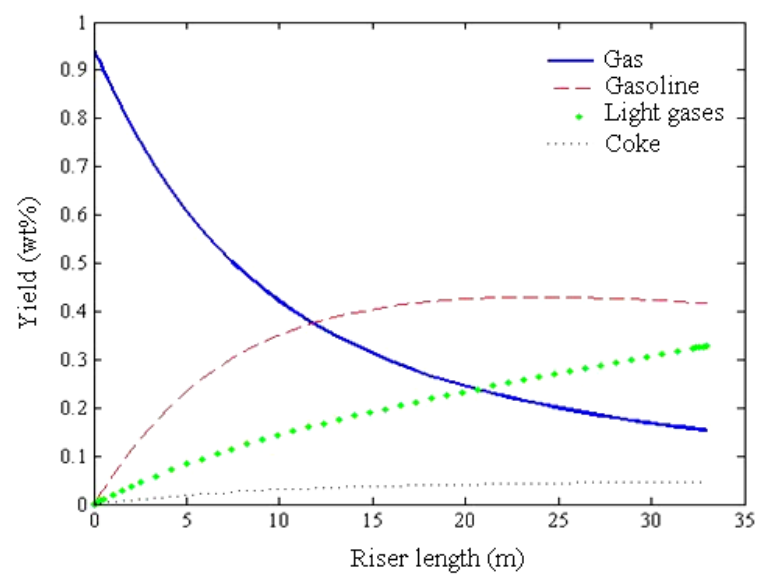

Fig. 4: Steady-state concentration profiles in the riser

\section{DISCUSSION}

This study, investigated a typical simulation results for base case (case 1) operating condition. It is noticed that in this case, the model prediction of the coke yield and the outlet temperature gives the lowest deviations from the plant data among the four cases investigated. In Fig. 3 the temperature profile of reactions in the riser has been illustrated, as it was expected, due to the nature of endothermic reaction, the temperature profile is descending, Fig. 4 depicts the predicted axial profiles in the riser. The model predicts that much of the gas oil conversion occurs in the first $5 \mathrm{~m}$ of the riser,

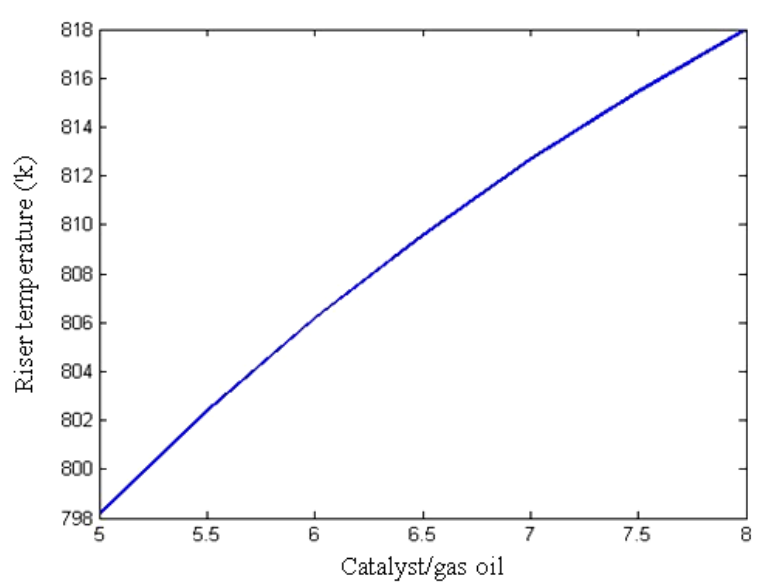

Fig. 5: Effect of changing catalyst-to-oil ratio on the riser temperature

which is correspondence with other FCC unit riser simulation (Berry et al., 2004; Kimm et al., 1994; Martin et al., 1992) and commercial data, There are a number of reasons for this, First, the bottom zone of the riser has a high catalysts concentration, In addition, this catalysts just have been reintroduced from the regenerator, has a higher temperature and activity than it does at higher axial location in the riser, Further more, the concentration of gas oil vapor is highest at the base of the riser in compared to that at higher axial locations, where reaction and molar expansion decrease the gas oil concentration, thus, the reaction rate of gas oil to products is greatest at the bottom of the riser, contributing to rapid conversion, Fig. 5 shows the influence of steady-state Catalyst-to-Oil Ratio (COR) on outlet temperature, so the rate of the cracking reactions will increase, Fig. 6 shows the profile of conversion along the axial coordinate. Figure 7 shows that the maximum gasoline yield was obtained at $80 \%$ conversion. Figure 8 shows the effect of changing inlet temperatures on gasoline yield along the axial coordinate in the riser. According to Fig. 8, because of high conversion in the initial section of riser, with increasing of inlet temperatures, gasoline yield increased, but after the gasoline yield passed through a maximum value, because of coke deposition, decreasing of the gasoline yield is evident. 
Am. J. Applied Sci., 7 (2): 221-226, 2010

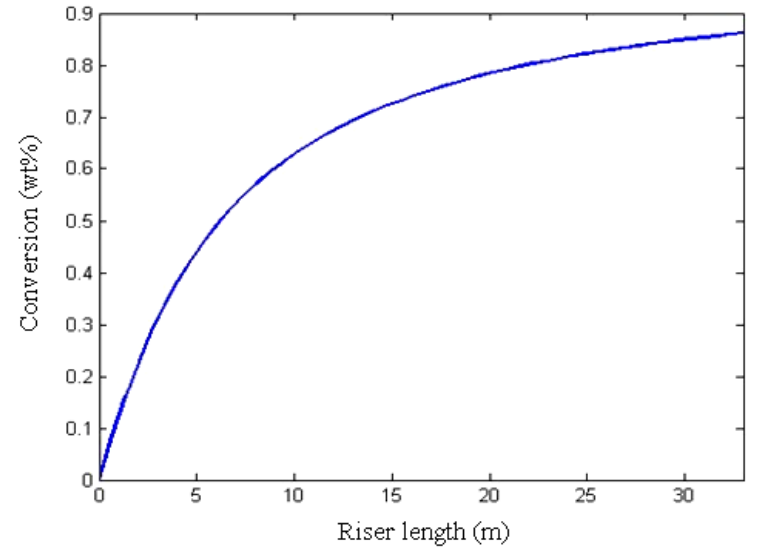

Fig. 6: Feed conversion Vs riser length

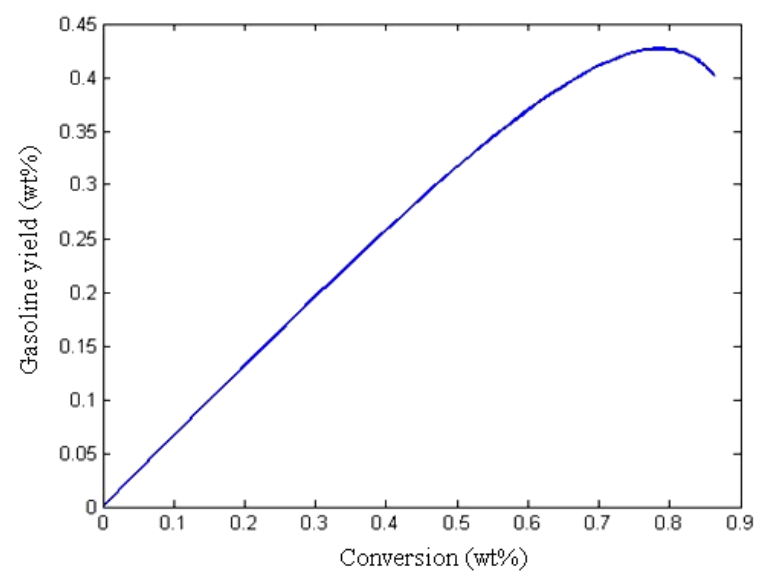

Fig. 7: Gasoline yield Vs conversion

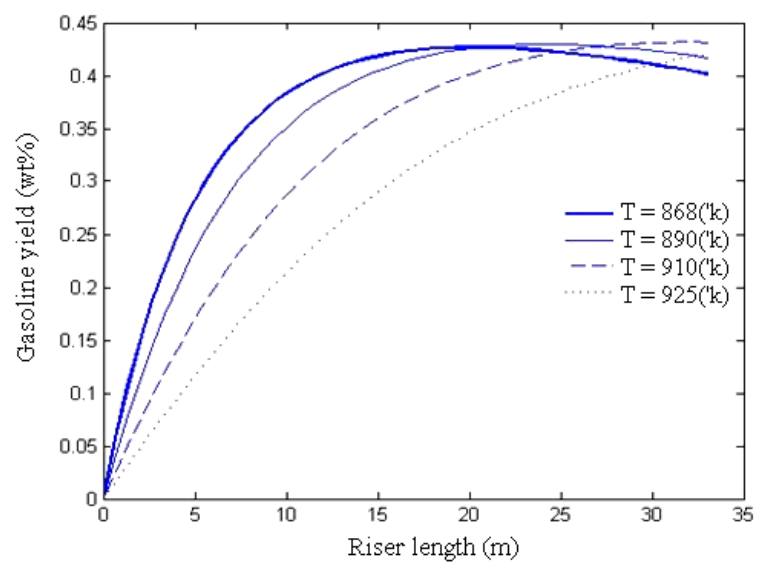

Fig. 8: Effect of changing inlet temperatures on gasoline yield along the axial coordinate in the riser

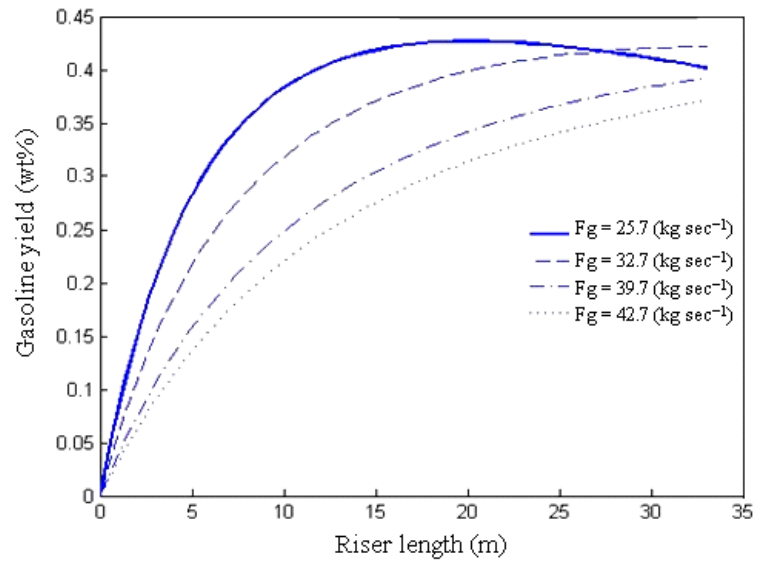

Fig. 9: Effect of changing different feed rates on gasoline yield along the axial coordinate in the riser

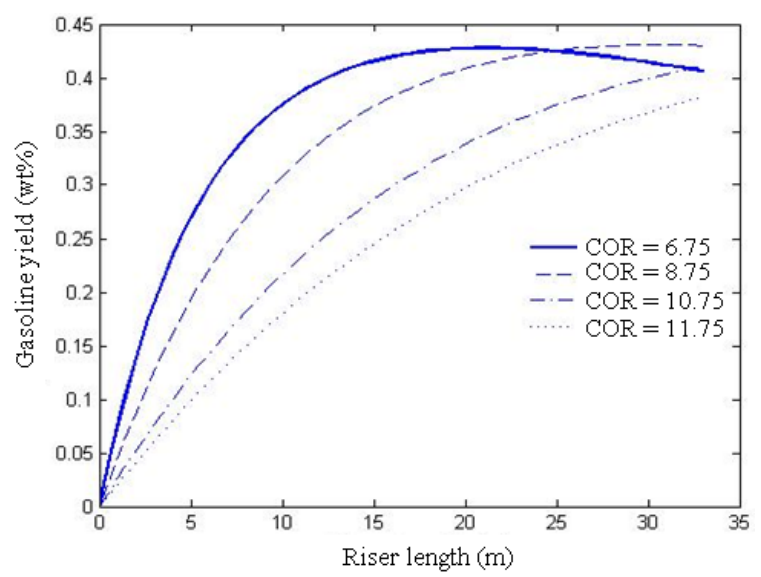

Fig. 10: Effect of changing different catalyst-to-oil ratio on gasoline yield along the axial coordinate in the riser

The highest yield of $42 \%$ was obtained at $913 \mathrm{k}$, It should be noted that this maximum point is a function of the feed quality, catalyst type and reaction temperature. Figure 9 and 10 show that increasing of input feed rates and catalyst-to-oil ratio, the gasoline yield decreases, because gas and catalyst velocities increase with increasing of input catalyst temperature, so the catalyst residence time will decrease. The short residence time minimizes gasoline cracking and coke yield (Kasata and Gupta, 2003).

\section{CONCLUSION}

A one-dimensional model of the riser section of FCC unit has been developed by combining a one 
dimensional predictive riser hydrodynamic model with the four-lump reaction kinetics model of Lee et al. (1989a). Four steady-state case studies corresponding to four different feed rates, feed quality (API) and catalyst-to-oil ratio have been considered to verify the model. In this study, investigated a typical simulation results for base case (case 1) operating condition. It is noticed that in this case, the model prediction of the coke yield and the outlet temperature gives the lowest deviations from the plant data among the four cases examined. Effect of the operating conditions on the system behavior has also been studied. The model predictions of the gas oil conversion, product yield and temperature were validated by comparison with plant data supplied by Ali and Rohani (1997).Very good agreement was found between the model predictions and the industrial data when the modified kinetic parameters reported by Ahari et al. (2008) were considered. The proposed model is suitable for off-line process simulation as well as on-line application, which is the basis of process optimization and advanced process control.

\section{REFERENCES}

Ahari, J.S., A. Farshi and K. Forsat, 2008. A mathematical modeling of the riser reactor in industrial FCC unit. Petroleum Coal, 50: 15-24. http://www.vurup.sk/pc/vol50_2008/issue2/pd f/PC_2_2008_Sadeghzadeh.pdf

Ali, H. and S. Rohani, 1997. Dynamic modeling and simulation of a riser-type fluid catalytic cracking unit. Chem. Eng. Tech., 20: 118-130. DOI: 10.1002/ceat.270200209

Ancheyta-Juarez, J., F. Lopez-Isunza and E. Aguilar-Rodriguez, 1999. 5-Lump kinetic model for gas oil catalytic cracking. Applied Catal. A: Gen., 177: 227-235. DOI: 10.1016/S0926$860 X(98) 00262-2$

Arandes, J.M. and H.I. de Lasa, 1992. Simulation and multiplicity of steady states in fluidized FCCUS. Chem. Eng. Sci., 47: 2535-2540. DOI: 10.1016/0009-2509(92)87089-9

Arbel, A., I.H. Rinard, R. Shinnar and A.V. Sapre, 1995. Dynamics and control of fluidized catalytic crackers. 2. Multiple Steady States and Instabilities. India Eng. Chem. Res., 34: 30143026. DOI: $10.1021 / \mathrm{ie} 00048 \mathrm{a} 013$

Berry, T.A., T.R. Mc Keen, T.S. Pugsley and A.K. Dalai, 2004.Two-dimensional reaction engineering model of the riser section of a fluid catalytic cracking unit. Ind. Eng. Chem. Res., 43: 5571-5581. DOI: 10.1021/ie0306877
Bollas, G.M., A.A. Lappas, D.K. Iatridis and I.A. Vasalos, 2007. Five-lump kinetic model with selective catalyst deactivation for the prediction of the product selectivity in the fluid catalytic cracking process. Catal. Today, 127: 31-43. DOI: 10.1016/j.cattod.2007.02.037

Corella, J. and E. Frances, 1991. On the kinetic equation of deactivation of Commercial Cracking (Fcc) Catalysts with Commercial Feedstocks. Catalysts Commerc. Feedstocks, 68: 375-381. DOI: 10.1016/S0167-2991(08)62657-9

Dupain, X. and M. Makkee and J.A. Moulijn, 2006. Optimal conditions in fluid catalytic cracking: A mechanistic approach. Applied Catal. A: Gen., 297: 198-219. DOI:10.1016/j.apcata.2005.09.009

Hagelberg, P. and I. Eilos, J. Hiltunen, K. Lipiäinen and V.M. Niemi, et al., 2002. Kinetics of catalytic cracking with short contact times. Applied Catal., 223: 73-84. DOI: 10.1016/S0926-860X(01)00744-X

Han, I.S. and C.B. Chung, 2001. Dynamic modeling and simulation of a fluidized catalytic cracking process. Part I: Process modeling. Chem. Eng. Sci., 55: 1951-1971. DOI: 10.1016/S0009509(00)00493-0

Kasata, R. and K. Gupta, 2003. Multi-objective optimization of an industrial fluidized-bed catalytic cracking units (FCCU) using elitist non dominated sorting genetic algorithm (GA) with the jumping genes operator. Ind. Eng. Chem. Res., 27: 17851800. DOI: 10.1016/S0098-1354(03)00153-4

Kimm, N.K., T.S. Pugsley and F. Berruti, 1994. Modeling the hydrodynamics of down flow gassolids reactors. Chem. Eng. Sci., 51: 2661-2666. DOI: 10.1016/0009-2509(96)00133-9

Kraemer, D., H.I. Delasa and M. Larocca, 1991. Deactivation of cracking catalyst in short contact time reactors: Alternative models. Ind. Eng. Chem. Res., 69: 355-360. DOI: 10.1002/cjce.5450690143

Lee, L.S., S.W.Yu, S.T. Cheng and W.Y. Pan, 1989b. Fluidized-bed catalyst cracking regenerator modelling and analysis. Chemical Eng. J., 40: 71-82. DOI: 10.1016/0300-9467(89)80048-6

Lee, L.S., Y.W. Chen, T.N. Huang and W.Y. Pan, 1989a. Four-lump kinetic model for fluid catalytic cracking process .Can. J. Chem. Eng., 67: 615-619. DOI: $10.1002 /$ cjce.5450670414

Martin, M.P., C. Derouin, P. Turlier, M. Forissier and G. Wild et al., 1992. Catalytic cracking in riser reactors: Core-annulus and elbow effects. Chem. Eng. Sci., 47: 2319-2324. DOI: 10.1016/00092509(92)87054-T

Weekman, V., 1968. Model of catalytic cracking conversion in fixed moving and fluid-bed reactors. Ind. Eng. Chem. Proc. Des. Dev., 7: 90-95. DOI: 10.1021/i260025a018 